\title{
Prevalence and Factors Associated with Polypharmacy among Elderly Persons.
}

\section{Sheref M. Eltaher and Eman M. Araby}

Department of Public Health and Community Medicine, Faculty of Medicine, Benha University, Benha, Egypt

Received: August, $2018 \quad$ Accepted: October, 2018

\section{Abstract}

Background: Polypharmacy especially in elderly is a challenging public health problem all over the world that leads to increased hospitalization, poor quality of life and represents an economic burden especially in developing countries like Egypt. Objectives: To estimate the prevalence of polypharmacy and identify associated factors among elderly persons. Method: A descriptive, cross-sectional study conducted from August to December 2017, in Benha city, Qalubiya Governorate, Egypt. Study population is 60 years elder and over. They were interviewed by the researcher using a standardized valid questionnaire. Results: A total of 300 elderly persons were enrolled. Approximately 67\%aged between 60 and 70 years, $73.7 \%$ of them live with their families, and $51.7 \%$ of them had a monthly income more than 2000 LE, $80 \%$ of them was non-smokers, and $85.3 \%$ of them reported using five or more medications. Logistic regression revealed that the significant predictors of polypharmacy use were sex (adjusted Odds Ratio (aOR), 0.1; 95\% CI 0.04-0.28, p <0.001), residence (aOR, 3.29 ; 95\% CI 1.18-9.14, $\mathrm{p}=0.02$ ), monthly income (aOR, 0.33 ; 95\% CI $0.13-0.18, \mathrm{p}=0.02$ ) and co-morbidity (aOR, 2.56; 95\% CI 1.75-3.74, $\mathrm{p}<0.001$ ). On the other hand, polypharmacy was not significantly associated with age (aOR, $0.84 ; 95 \%$ CI $0.34-2.07, \mathrm{p}=0.71)$, smoking (a OR, 0.83; 95\% CI 0.23-2.88, $\mathrm{p}=0.77$ ), educational level (a OR, 1.19; 95\% CI 0.62-2.29, $\mathrm{p}$ $=0.59)$ or marital status $(\mathrm{aOR}, 0.71 ; 95 \%$ CI $0.47-1.07, \mathrm{p}=0.1)$ Conclusion: The prevalence of polypharmacy was $85.3 \%$. Sex, residence, monthly income and co-morbidity were significant predictors of polypharmacy.

Keywords: Polypharmacy; Elderly; Prevalence; Egypt.

Corresponding Author: Sheref M. Eltaher Email: sherefmoh@gmail.com

\section{Introduction}

World Health Organization (WHO) report anticipated that between 2015 and 2050, the percentage of the world's population over 60 years will nearly double from about $12 \%$ to $22 \%{ }^{1}$ Egyptian census 2017 , reported that people above 60 years represented $6.9 \%$ of total Egyptian population. ${ }^{2}$ Elderly people usually suffer from multiple co-morbidities and, as a result, become exposed to multiple drugs; this situation is often referred to as "polypharmy".3

Polypharmacy is defined as the use of several different medications by one patient at the same time. ${ }^{4}$ Sometimes it is estimated it to be 2 to 5 drugs, but the most commonly used definition is the simultaneous utilization of 5 to 7 drugs $^{3}$ and over seven medications is termed excessive polypharmacy. ${ }^{5}$ 
Polypharmacy especially in elderly is a challenging public health problem all over the world. ${ }^{1}$ Geriatric patients regularly experience the ill effects of changed pharmacokinetics, lessened medication clearance, and cognitive deficits. ${ }^{6}$ Accompanying utilization of various medications may result in higher adverse drug reactions, drug-drug interaction and bring down adherence to treatment and cognitive decline. ${ }^{7}$ In addition to increase need for care, higher healthcare cost and elevated hospital admission rate. ${ }^{4}$

An adverse drug event is defined as "an injury due to a medication," and occurs in approximately $(35 \%)$ of elderly outpatients and $(40 \%)$ of elderly hospitalized patients. ${ }^{8,9}$ The most common type of $\mathrm{ADE}$ is an adverse drug reaction (ADR), which is characterized as a noxious and unintended response that occurs at normal doses of a medication. ${ }^{10}$ ADRs may be Type A or Type $B$ reactions. Type A reactions are related to the mechanism of action, for example, bleeding on warfarin, and this may occur if drug interactions increase medication's plasma levels. Type B reactions are random, like anaphylaxis. The risk of ADRs is $(15 \%)$ with two medications and rises to $(58 \%)$ with five medications and (82\%) with over seven medications. The four most common drug groups associated with preventable drug-related admissions are anti-platelets; diuretics; NSAIDs and anti-coagulants. $^{11}$

The prevalence of polypharmacy in the elderly had been assessed by many studies. It ranged between $(39 \%)^{12}$ and $(45 \%)^{13}$ in developed countries. Egyptian study estimated it to be $(56 \%)$ in rural communities $^{14}$, but still there is rarity in studies evaluating the prevalence of polypharmacy in developing countries and to our knowledge, it is the first study estimating the prevalence of polypharmacy in Benha city, Qalubiya Governorate.

\section{Method}

Study design: This is a descriptive crosssectional multicenter study conducted in Benha city, Qalubiya Governorate, Egypt between August and December 2017.

Sample size: The sample size was calculated using EPI-Info (Epidemiological information package) software version 6.1, C.I (Confidence Interval) $95 \%$, Power $80 \%$. The sample was 271 people we increase $10 \%$ so the sample size needed was 300 people.

Data collection methods: The researcher used the face-to-face structured interview approach, based on standardized questionnaire. The data for analysis was collected from patients in different health care institutions including Benha University Hospital and Health Insurance clinics.

Sample selection: The study sample was selected according to certain inclusion criteria: Being 60 years old or more, Be a resident of Banha city, The patients had at least one chronic pathological condition in the following clusters: cardio-metabolic (consisting of diabetes, heart disease or hypertension), musculoskeletal (consisting of arthritis or osteoporosis), and respiratory (consisting of COPD or asthma), GIT (hepatic or gastric diseases) and psychological disorders (depression and sleep disorders), Have been taking at least two drugs on regular base in the last six months and His health condition is stable and he is not a hospital resident at the time of study.

For five months, study participants were selected from elderly attending out-patient clinics. The researcher interviewed patients on Saturday and Tuesday at Banha University Hospital and on Sunday and Wednesday at health insurance clinics. 
Table (2): Comparison between polypharmacy and no polypharmacy regarding sociodemographic data:

\begin{tabular}{|c|c|c|c|c|c|c|c|}
\hline & & \multicolumn{2}{|c|}{$<5$ drugs } & \multicolumn{2}{|c|}{$\geq 5$ drugs } & \multirow{2}{*}{$\mathbf{X}^{2}$} & \multirow{2}{*}{ p-value } \\
\hline & & No. & $\%$ & No. & $\%$ & & \\
\hline \multirow{3}{*}{ Age } & $60-70$ & 35 & 79.5 & 165 & 64.5 & \multirow{3}{*}{8.5} & \multirow{3}{*}{$* * 0.01$} \\
\hline & $71-80$ & 6 & 13.6 & 85 & 33.2 & & \\
\hline & more than 80 & 3 & 6.8 & 6 & 2.3 & & \\
\hline \multirow{2}{*}{ Sex } & Male & 13 & 29.5 & 149 & 58.2 & \multirow{2}{*}{12.4} & \multirow{2}{*}{$* *<0.001$} \\
\hline & Female & 31 & 70.5 & 107 & 41.8 & & \\
\hline \multirow{3}{*}{ Residence } & Geriatric home & 0 & 0.0 & 3 & 1.2 & \multirow{3}{*}{4.4} & \multirow{3}{*}{0.1} \\
\hline & With family & 38 & 86.4 & 183 & 71.5 & & \\
\hline & Alone & 6 & 13.6 & 70 & 27.3 & & \\
\hline \multirow{3}{*}{$\begin{array}{l}\text { Monthly } \\
\text { Income }\end{array}$} & Less than 1000 & 12 & 27.3 & 94 & 36.7 & \multirow{3}{*}{12.1} & \multirow{3}{*}{$* * 0.002$} \\
\hline & $1000-2000$ & 0 & 0.0 & 39 & 15.2 & & \\
\hline & More than 2000 & 32 & 72.7 & 123 & 48.0 & & \\
\hline \multirow{5}{*}{$\begin{array}{l}\text { Educational } \\
\text { level }\end{array}$} & Illiterate & 9 & 20.5 & 47 & 18.4 & \multirow{5}{*}{21.2} & \multirow{5}{*}{$* *<0.001$} \\
\hline & Basic education & 3 & 6.8 & 42 & 16.4 & & \\
\hline & Secondary education & 3 & 6.8 & 45 & 17.6 & & \\
\hline & University education & 15 & 34.1 & 99 & 38.7 & & \\
\hline & Postgraduate & 14 & 31.8 & 23 & 9.0 & & \\
\hline \multirow{3}{*}{$\begin{array}{l}\text { Marital } \\
\text { Status }\end{array}$} & Married & 21 & 47.7 & 109 & 42.6 & \multirow{3}{*}{7.02} & \multirow{3}{*}{$* 0.03$} \\
\hline & Divorced & 3 & 6.8 & 3 & 1.2 & & \\
\hline & Widow & 20 & 45.5 & 144 & 56.2 & & \\
\hline \multirow{2}{*}{ Smoking } & Yes & 6 & 13.6 & 54 & 21.1 & \multirow{2}{*}{1.3} & \multirow{2}{*}{0.3} \\
\hline & No & 38 & 86.4 & 202 & 78.9 & & \\
\hline \multirow{5}{*}{$\begin{array}{l}\text { Co- } \\
\text { morbidity }\end{array}$} & One & 0 & 0.0 & 6 & 2.3 & \multirow{5}{*}{10.7} & \multirow{5}{*}{$* 0.03$} \\
\hline & Two & 14 & 31.8 & 59 & 23.0 & & \\
\hline & Three & 16 & 36.4 & 51 & 19.9 & & \\
\hline & Four & 7 & 15.9 & 78 & 30.5 & & \\
\hline & More than 4 & 7 & 15.9 & 62 & 24.2 & & \\
\hline
\end{tabular}

*significant; ** Highly significant

and percentage. The statistical significant differences in polypharmacy and factors affecting it were done with Chi square test $\left(X^{2}\right)$. Logistic regression analysis was done to detect predictors of polypharmacy. $\mathrm{P}$ value $<0.05$ was considered significant.

\section{Ethical Considerations}

Ethical approval was granted by ethical committee at Benha Faculty of Medicine and verbal consent was also obtained from each participant before conducting interview. Participants were told that the obtained information is confidential.

\section{Results}

As table (1) shows, among the 300 elderly persons surveyed, $66.7 \%$ were between 60 and 70 years old, $54 \%$ were males, $73.7 \%$ live with their families, $51.7 \%$ had income more than $2000 \mathrm{LE}$, and $80 \%$ were nonsmokers. In addition, $38 \%$ had university education, while $18.7 \%$ were illiterate. The median (IQR) for co-morbidities was 4 $(2 \%)$. In terms of polypharmacy, 256 $(85.3 \%)$ individuals reported using five or more medications (Table 1).

(Table 2) revealed the statistically significant difference between polypharmacy and non-poly-pharmacy groups regarding age (most of non-poly-pharmacy group belonged to the age group 60-70 
Table (3): Predictors of polypharmacy among elderly patients:

\begin{tabular}{lcccc}
\hline \multicolumn{1}{c}{ Predictors } & \multicolumn{2}{c}{ Bivariate logistic regression } & \multicolumn{2}{c}{ Multivariate logistic regression } \\
\hline OR $(95 \% \mathrm{CI})$ & P-value & \multicolumn{1}{c}{ Adjusted OR } & P-value \\
\hline Sex & $1.49(0.77-2.87)$ & 0.23 & $0.84(0.34-2.07)$ & 0.71 \\
\hline Smoking & $0.3(0.15-0.6)$ & $* 0.001$ & $0.1(0.04-0.28)$ & $*<0.001$ \\
\hline Residence & $0.59(0.23-1.47)$ & 0.26 & $0.83(0.23-2.88)$ & 0.77 \\
\hline Monthly Income & $1.99(0.89-4.42)$ & 0.09 & $3.29(1.18-9.14)$ & $* 0.02$ \\
\hline Educational level & $0.66(0.44-0.94)$ & $* 0.03$ & $0.33(0.13-0.81)$ & $* 0.02$ \\
\hline Marital Status & $0.75(0.58-0.97)$ & $* 0.03$ & $1.19(0.62-2.29)$ & 0.59 \\
\hline Co-morbidity & $1.18(0.85-1.62)$ & 0.32 & $0.71(0.47-1.07)$ & 0.1 \\
\hline & $1.34(1.04-1.7)$ & $* 0.02$ & $2.56(1.75-3.74)$ & $* 0.000$ \\
\hline
\end{tabular}

years., while those belonged to the age group 70 to 80 were mainly from a polypharmacy group) ( $\mathrm{p}=0.01)$, Sex $(58.2 \%$ of poly-pharmacy group were males, while $(70.5 \%)$ of non poly-pharmacy group were females $)(\mathrm{p}<0.001)$, Monthly income (48\% of poly pharmacy group and $72.7 \%$ of non poly-pharmacy group were more than 2000 L.E. per month .poly- pharmacy group showed lower income than the other group , and this difference was statistically significant $(\mathrm{p}=0.002)$. As regards educational level, only $47.7 \%$ of polypharmacy group were university or postgraduate educated $v s$. $65.9 \%$ of the other group which reflected lower level of education of poly-pharmacy group $(\mathrm{p}<0.001)$.As regards marital status $(47.7 \%)$ of non poly pharmacy were married, while the majority of polypharmacy group (56.2\%) were widows ( $\mathrm{p}=0.03$ ) and finally, having $\geq 4 \mathrm{Co}-$ morbidities were higher among polypharmacy group (54.6\%) vs. ( $31.8 \%)$ for non polypharmacy group $(\mathrm{p}=0.03)$. There was no statistically significant difference regarding Residence $(\mathrm{p}=0.1)$ and Smoking $(\mathrm{p}=0.3)$.

Table (3) revealed that the following were significant predictors of polypharmacy use, sex (OR:0.3 ,95\% CI 0.15-0.6, p<0.001), monthly income (OR: $0.66,95 \%$ CI $0.44-$ 0.94,p $=0.03$ ) ,educational level (OR:0.75 ,95\% CI $0.58-0.97, \mathrm{p}=0.03$ )and finally presence of Co-morbidity (OR: $1.34,95 \%$
CI 1.04-1.7, $\mathrm{p}=0.02)$.Multivariate logistic regression revealed that the following were the significant predictors of polypharmacy, sex (adjusted odds ratio (aOR), 0.1; 95\% CI 0.04-0.28, p <0.001), residence (aOR, 3.29 ; 95\% CI 1.18-9.14, p = 0. 02), monthly income (aOR, 0.33 ; 95\% CI 0.13 $0.18, \mathrm{p}=0.02$ ) and Co-morbidity (aOR, $2.56 ; 95 \%$ CI 1.75-3.74, p <0.001). However, polypharmacy was not significantly associated with Age (aOR, $0.84 ; 95 \%$ CI $0.34-2.07, \mathrm{p}=0.71)$, Smoking (aOR, 0.83; 95\% CI 0.23-2.88, p $=0.77$ ), Educational level (aOR, 1.19; 95\% CI 0.62-2.29, $\mathrm{p}=0.59$ ) and Marital status (aOR, 0.71; 95\% CI 0.47-1.07, p=0.1).

\section{Discussion}

In this study, the prevalence of polypharmacy was $85.3 \%$, which is nearly similar to the results of previous studies conducted in Mexico ${ }^{16}$, Abu Dhabi ${ }^{17} \&$ Saudi Arabia $^{18}(84.5 \%$, 89\% and $89 \%$ respectively). On the contrary, our rate was higher than that of a previous Egyptian study estimated it to be $56 \%$ in rural communities $^{14}$ and another study performed in elderly patients on discharge from a tertiary care hospital in Oman which found it $(76.3 \%) .{ }^{4}$ The high rate of polypharmacy among our study group can be attributed to many factors like multiple co-morbidities they have, the culture of taking medications without medical prescription, easy access to over-the- 
counter medicines and higher socioeconomic condition in urban areas in comparison to rural ones which enable elderly people to have medications at their own expense. Though the high socioeconomic standard in developed and Arab countries in Gulf area, but there is very strict supervision on private pharmacy which limits easy access to over the counter medications.

This study found a significant difference between polypharmacy \& no polypharmacy group regarding age, sex, educational level, monthly income, marital status \& co-morbidities. Polypharmacy group was older, male more than female, of lower educational level, lower monthly income, the majority were widows with multiple co morbidities $>4$. Some of our findings come in agreement with results of previous studies reported a significant association between polypharmacy and sex ${ }^{19}$ level of education, and/or a history of diabetes or hypertension. ${ }^{20}$ Patient conduct and understanding can affect polypharmacy. Deprived knowledge about medication may lead to extra or needless drugs by physicians who don't know patients' current or previous medication list, this may be due to movement of patients between primary and secondary care. That result in a 'prescribing cascade', in which new symptom appears and the physicians don't know its source and write another drug for it and so on. Visiting more than one physician in different sites also rise the risk of repeated medications or drug interactions. ${ }^{21}$

This study results differed from another study found no association between polypharmacy and age, sex, educational level, or number of co-morbidities. These differences could be the result of differences in the characteristics of the populations studied and/or sample size.

\section{Limitations of this study}

Inability to generalize the results of this study for elderly in different countries due to socio-demographic \& economic variations and multiple accepted definitions of polypharmacy.

\section{Conclusion}

Polypharmacy is a common phenomenon among old males, with low educational level. The majority of polypharmacy group were widows with multiple co-morbidities ( $\geq 4$ diseases). Sex, residence, monthly income and number of co-morbidities are significant predictors of this phenomenon.

\section{Recommendations}

Ministry of health should strictly supervise private pharmacies to limit over-thecounter medicines and recent medical prescription should be mandatory for having drugs. Also, periodic medical evaluation must be done especially for old people with multiple chronic diseases to minimize the amount of taken medications as possible as we can to decrease drug interaction.

\section{Acknowledgment}

The authors are thankful for all participants for their collaboration.

\section{References}

1. World Health Organization Report (2015). Facts About Ageing.

2. Central Agency for Public Mobilization and Statistics (CAMPAS), Census Egypt 2017.

3. Al-Hashar A, Al Sinawi H, Al Mahrizi A, Al-Hatrushi M (2016): Prevalence and Covariates of Polypharmacy in Elderly Patients on Discharge from a Tertiary Care Hospital in Oman; Oman Medical Journal (2016), 31, 6: 421-425.

4. Duerden M , Avery $\mathrm{T}$, \& Payne R. (2013).Polypharmacy and medicines optimization.

5. Making it safe and sound. Retrieved fromwww.kingsfund.org.uk/sites/files/kf/field/ field_publication_file/polypharmacy-andmedicines-optimisation-kingsfund-nov13.pdf.

6. Royal Pharmaceutical Society (2013). Promoting Pharmacy. Retrieved from www.rpharms.com/promoting-pharmacypdfs/mo - evidence-inpractice. 
7. Dagli RJ, Sharma A. Polypharmacy(2014): a global risk factor for elderly people. J Int Oral Health 2014 Nov-dec;6(6):i-ii.

8. Almeida N, Reiners A, Azevedo R, Silva A, Cardoso J, Souza L (2017). Prevalence of and factors associated with polypharmacy among elderly persons resident in the community. Rev. bras. geriatr. gerontol; 20(1): 138-148.

9. Institute of Medicine (2006). Preventing medication errors. Washington, DC: National Academies Press.

10.Hohl CM, Dankoff J, Colacone A, Afilalo M (2001). Polypharmacy, adverse drug-related events, and potential adverse drug reactions in elderly patients presenting to an emergency department. Ann Emerg Med.; 38:666-71.

11.Edwards IR, Aronson JK (2000). Adverse drug reactions: definitions, diagnosis, and management. Lancet; 356:1255-9.

12.Howard R, Avery A, Slavenburg S, Royal S, Pipe G, Lucassen P, Pirmohamed M. (2006). Which drugs cause preventable admissions to hospital? A systematic review. British Journal of Clinical Pharmacology, 63(2), 136-147.

13. Charlesworth CJ, Smit E, Lee DS, Alramadhan F, Odden MC (2015). Polypharmacy adults aged 65 years and older in the United States: 1988-2010. J gerontol Ser ABiol Sci Med Sci. 2015;70(8):989-95.

14.Banerjee A, Mbamalu D, Ebrahimi S, Khan AA, Chan TF (2011). The prevalence of polypharmacy in elderly attenders to an emergency department - a problem with a need for an effective solution International. J Emerg Med [Internet]. 2011 [acessoem $30 \mathrm{dez}$. 2014];4(1):1-8.

15.Sarah A. Hamza, Mohamed Z. Abdel wadoud, Ismail A. A. Kandil and Ahmed K. Mortagy(2010). Polypharmacy and inappropriate medication use among elderly persons in an Egyptian rural area. ast Journal of Age and Ageing 2009; Volume 6, Issue 5 Middle East Journal of Age and Ageing Volume 7, Issue 4, August 2010.

16.Akkawi F (2008). Prevalence and Risk Factors affecting polypharmacy among elderly patients in the North of West Bank. Nablus, Palestine. An-Najah National University.

17.Martínez-Arroyo Jl, Gómez-García A, Sauceda-Martínez d(2014). Polypharmacy prevalence and potentially inappropriate drug prescription in the elderly hospitalized for cardiovascular disease. Gac Med Mex 2014 dec;150(Suppl 1):29-38.

18. Mubarak N. Makramalla E, Umniya A, Rao $P$ (2014). Prevalence of Poly-pharmacy in the Elderly: Implications of Age, Gender, Comorbidities and drug Interactions. SOJ Pharm Pharm Sci 2014;1(3):1-7.

19.Salih S, Yousuf $M$, durihim $H$, Almodaimegh H, Tamim H(2013). Prevalence and associated factors of polypharmacy among adult Saudi medical outpatients at a tertiary care center. J Family Community Med 2013 Sep;20(3):162-167.

20.Linjakumpu T, Hartikainen S, Klaukka T, Veijola J, Kivelä SL, Isoaho R(2002). Use of medication and polypharmacy are increasing among the elderly. J ClinEpidemiol. 2002; 55:809-81.

21. Moen J, Antonov K, Larsson CA, Lindblad U, Nilsson JL, Råstam L, et al(2009). Factors associated with multiple medication use in different age groups. Ann Pharmacother. 2009; 43:1978-85.

22.Negar Golchin, Scott H. Frank, April Vince, Lisa Isham, and Sharon B. Meropol. Polypharmacy in the elderly. J Res Pharm Pract. 2015 Apr-Jun; 4(2): 85-88. 